\section{Does current pre-hospital analgesia effectively reduce pain in children caused by trauma, within a UK ambulance service? A service evaluation}

\author{
Gregory Adam Whitley* \\ East Midlands Ambulance Service NHS Trust \\ gregory.whitley@emas.nhs.uk
}

\section{Fiona Bath-Hextall}

University of Nottingham

fiona.bath-hextall@nottingham.ac.uk
British Paramedic Journal 2017, vol. 1(4) 21-28

(C) The Author(s) 2017 ISSN 1478-4726

Reprints and permissions: info@class.co.uk

The BPJ is the journal of the

College of Paramedics: www.collegeofparamedics.co.uk

\begin{abstract}
Introduction - Pain is one of the most common symptoms presented by patients of all ages to ambulance services, however very few children receive analgesia. Analgesic treatment of prehospital injured children is viewed as 'suboptimal'. The aim of this study was to explore current analgesia given to traumatically injured children in the pre-hospital setting and examine whether a clinically meaningful reduction in pain was achieved.

Methods - We evaluated electronic patient report forms over a two-year period (2013-2014) within a UK ambulance service NHS trust. All traumatically injured children within the age range 1-17 with a clinical impression of a fracture, dislocation, wound or burn were included. Patients with a Glasgow Coma Scale of $<15$ were excluded. The outcome measure was a reduction in numeric pain rating scale or Wong and Baker faces of $\geq 2$ out of 10 .

Results - Of the evaluable patients $(\mathrm{N}=11,317), 90.8 \%$ had a documented pain score, or a reason why a pain score could not be documented. For patients reporting pain ( $N=7483), 51.6 \%$ $(n=3861)$ received analgesia, 9.6\% $(n=717)$ received no analgesia but did receive alternative treatment and $38.8 \%(n=2905)$ received no analgesia and no alternative treatment. Morphine sulphate IV, oral morphine, Entonox, paracetamol suspension and poly-analgesia all achieved a clinically meaningful median reduction in pain score; -3.0 (IQR, -5.0 to -2.0$),-2.0(-5.0$ to -2.0$)$, $-2.0(-4.0$ to -1.0$),-2.0(-4.0$ to 0.0$)$ and $-3.0(-4.0$ to -1.0$)$, respectively.

Conclusions - Analgesia administered to traumatically injured children in the pre-hospital setting within this UK ambulance service NHS trust produces clinically meaningful reductions in pain for these patients. The concern is that a large number of patients received neither analgesia nor alternative treatment. There is a real need to identify barriers to analgesia administration in this patient group.
\end{abstract}

\title{
Keywords
}

emergency medical services; paediatrics; pain management

\section{* Corresponding author:}

Gregory Adam Whitley, East Midlands Ambulance Service NHS Trust, Audit and Research Department, Cross O'Cliff Court, Bracebridge Heath, Lincoln LN4 2HL, UK. 


\section{Introduction}

Pain is one of the most common symptoms presented by patients of all ages to ambulance services (Joint Royal Colleges Ambulance Liaison Committee (JRCALC), 2016). Three studies found that very few children in pain receive analgesia pre-hospitally (Hennes, Kim, \& Pirrallo, 2005; Shaw, Fothergill, \& Virdi, 2015; Swor, McEachin, Seguin, \& Grail, 2005). Currently analgesic treatment of pre-hospital traumatically injured children is suboptimal (Samuel, Steiner, \& Shavit, 2015).

When considering analgesic administration, the child's pain must first be assessed. A number of tools exist to assess pain, including but not limited to the numeric pain rating scale (NPRS), Wong and Baker faces and the Face Legs Activity Cry and Consolability (FLACC) scale (JRCALC, 2016).

Within the ambulance service that this evaluation was conducted in, paramedics carry four different analgesics: paracetamol (tablets, suspension and intravenous), ibuprofen (tablets), Entonox (inhaled) and morphine (oral and intravenous). Ambulance technicians can administer paracetamol (tablets and suspension), ibuprofen (tablets) and Entonox (inhaled).

Each of these analgesics has disadvantages. Oral medications are slow to act (Halbsguth, Rentsch, Eich-Höchli, Diterich, \& Fattinger, 2008; JRCALC, 2016) and intravenous access is painful and difficult to achieve (Reigart et al., 2012). One study found that inhaled Entonox was effective in the majority of patients aged 2 to $16(80.5 \%)$, leaving the remainder in pain (Heinrich, Menzel, Hoffmann, Berger, \& Schweinitz, 2015). However, inhaled analgesics are difficult to administer to distressed and uncooperative children (Murphy et al., 2014). Intramuscular morphine sulphate is only recommended for patients with major trauma, cardiac conditions or shock, where the intravenous and oral routes are not optimal (JRCALC, 2016).

In order to better understand the effectiveness of pre-hospital analgesia administered to traumatically injured children within the UK a service evaluation was performed.

\section{Methods}

\section{Aim}

The aim of the service evaluation was to establish whether current analgesia can produce a clinically meaningful reduction in pain when treating traumatically injured children within a UK ambulance service NHS trust.

\section{Design}

A service evaluation was undertaken including all children aged 1 to 17 years attended in the pre-hospital setting by ambulance service clinicians with a clinical impression of a fracture, dislocation, wound or burn. Patients up to 17 years were included because the UK legal age for adulthood is achieved at 18 years, and patients below this age may still be immature and naïve to traumatic pain. The lower age limit was selected as this was the minimum age for morphine administration (JRCALC, 2016). Patients with a Glasgow Coma Scale of $<15$ at any time were excluded, as less conscious patients may not provide accurate pain reporting.

\section{Data collection}

Data were collected from the electronic database of patient report forms (PRFs) over a two-year period (1 January 2013 to 31 December 2014). Paper PRFs were not included due to the manual data extraction requirement being unfeasible given the resource and time constraints. Therefore, data included: age (years), sex, injury type, treatment administered (pharmacological and nonpharmacological), time of treatments, pain scores, pain score times, Glasgow Coma Scale and clinician level (paramedic/technician).

\section{Outcomes}

\section{Primary outcome}

The primary outcome was to establish which analgesics achieve a clinically meaningful reduction in pain using the NPRS (0-10) or Wong and Baker pain scale $(0,2,4$, $6,8,10)$. A reduction in pain of 2 or more on the NPRS or Wong and Baker was deemed clinically meaningful. This ambulance service does not routinely use a pre-verbal pain scoring tool such as FLACC.

\section{Secondary outcomes}

Secondary outcomes were to:

- determine the prevalence of pain scoring in traumatically injured children;

- determine the prevalence of analgesic use in traumatically injured children who report a pain score of 1-10 (NPRS) or 2-10 (Wong and Baker);

- $\quad$ establish which analgesics are most commonly used by paramedics and ambulance technicians;

- $\quad$ and establish which analgesics have the greatest pain score reduction per minute.

\section{Analysis}

The statistical analysis was performed using SPSS (versions 22 and 23). The primary outcome was assessed by calculating the average pain score reduction per analgesic and comparing it against the 'standard' (reduction in pain of $\geq 2$ out of 10 ). We used the following definition to determine a clinically meaningful reduction in pain: reduction in pain of $\geq 2$ out of 10 on the NPRS or Wong and Baker scale (Bulloch \& Tenenbein, 2002; Farrar, Berlin, \& Strom, 2003; Farrar, Young, LaMoreaux, 
Werth, \& Poole, 2001; Myrvik et al., 2013). Where patients received two or more analgesics, these were grouped and termed 'poly-analgesia'.

The first three secondary outcomes were determined by establishing the percentage difference. For the purpose of this service evaluation, data were split into mild (1-3), moderate (4-6) and severe (7-10) pain. The primary and secondary outcome data were skewed, therefore nonparametric testing was used. The significance level of the Kruskal-Wallis test was adjusted to 0.01 after the Bonferroni correction was made.

Ibuprofen (tablets) was not included in the analysis due to its limited usage. Forty-eight patients received ibuprofen, however 40 were excluded for the following reasons: duplicates $(n=3)$, no pain score $(n=2)$, pain score zero $(n=1)$, alternative treatment $(n=4)$, no preand post-analgesic pain score $(n=30)$. This left three patients who received ibuprofen only, and five patients who received ibuprofen along with other analgesics (polyanalgesia). Performing analysis on such small numbers would not be ideal, therefore these have been excluded as 'no morphine, Entonox, oral morphine, paracetamol tablets or paracetamol suspension administered' $(\mathrm{n}=3)$ and 'received alternative analgesia' $(n=5)$ (see Figure 1).

\section{Approvals}

Full NHS approval was obtained before the study was commenced. Full ethical approval was not required.

\section{Results}

All child electronic PRFs from 1 January 2013 to 31 December 2014 were gathered initially $(\mathrm{N}=46,281)$. These were filtered by clinical impression to include fractures, dislocations, wounds and burns. This produced 12,809 patients for data extraction. A further 1492 patients were excluded for having either no initial GCS or a GCS $<15$ at any time. Thus, 11,317 patients were analysed. Patient demographics can be seen in Table 1.

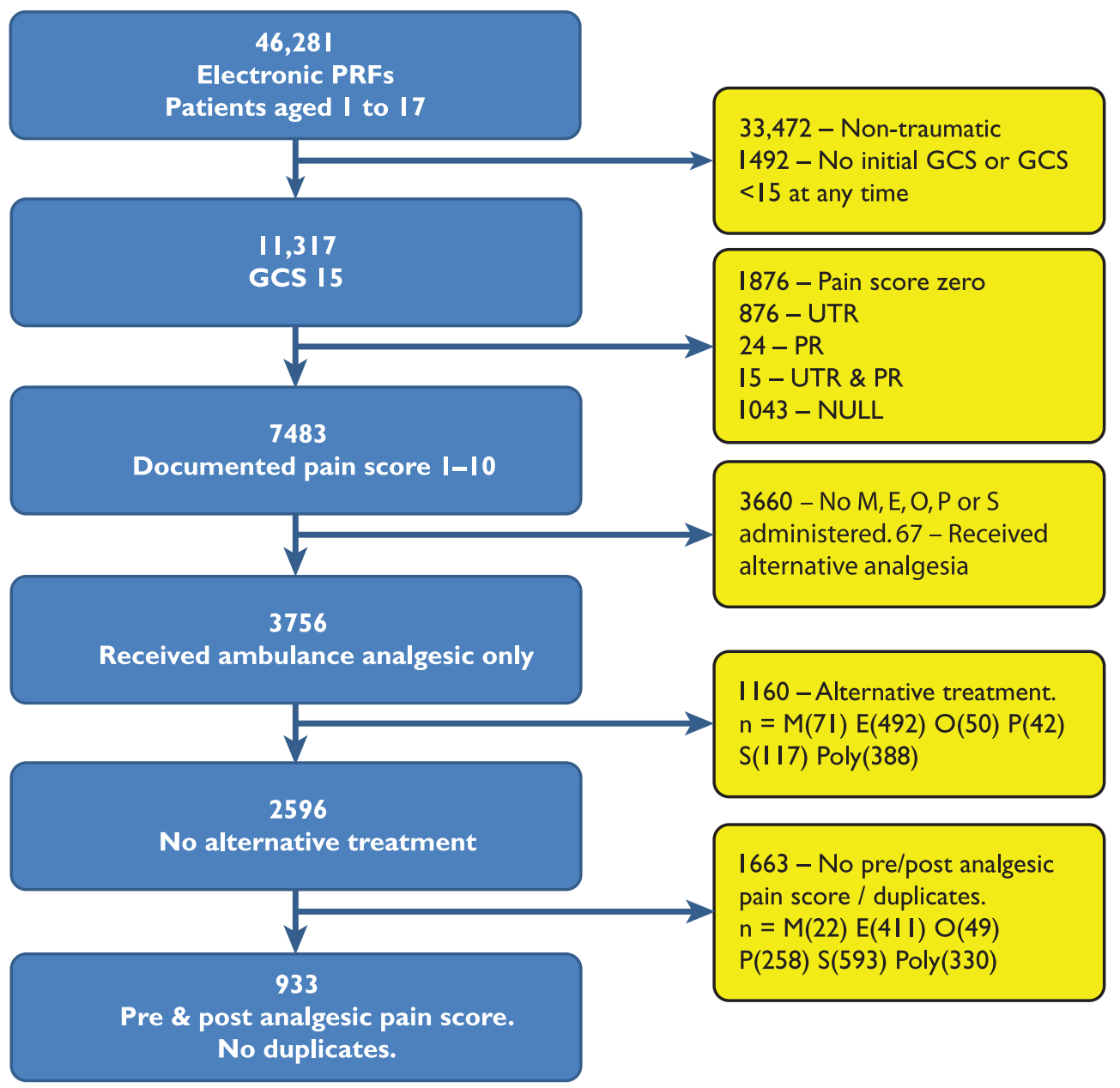

Figure I. Patient flow diagram illustrating all the patients excluded from the primary outcome.

Abbreviations: GCS = Glasgow Coma Scale; NULL = no data entered; UTR = unable to record; $P R=$ patient refused; $\mathrm{M}=$ morphine sulphate intravenous; $\mathrm{E}=$ Entonox; $\mathrm{O}=$ oral morphine; $\mathrm{P}=$ paracetamol tablets; $\mathrm{S}=$ paracetamol suspension; Poly = poly-analgesia. 
Table I. Demographics of patient population.

\begin{tabular}{|c|c|c|c|c|c|}
\hline Age (years) & $\mathrm{n}$ & $\%$ of total* & Sex & $\mathrm{n}$ & $\%$ of total** \\
\hline \multirow[t]{2}{*}{ I } & 918 & 8.1 & Male & 513 & 55.9 \\
\hline & & & Female & 373 & 40.6 \\
\hline \multirow[t]{2}{*}{2} & 826 & 7.3 & Male & 490 & 59.3 \\
\hline & & & Female & 313 & 37.9 \\
\hline \multirow[t]{2}{*}{3} & 669 & 5.9 & Male & 382 & 57.1 \\
\hline & & & Female & 268 & 40.1 \\
\hline \multirow[t]{2}{*}{4} & 531 & 4.7 & Male & 347 & 65.3 \\
\hline & & & Female & 170 & 32.0 \\
\hline \multirow[t]{2}{*}{5} & $47 I$ & 4.2 & Male & 273 & 58.0 \\
\hline & & & Female & 188 & 39.9 \\
\hline \multirow[t]{2}{*}{6} & 379 & 3.3 & Male & 231 & 60.9 \\
\hline & & & Female & 135 & 35.6 \\
\hline \multirow[t]{2}{*}{7} & 385 & 3.4 & Male & 240 & 62.3 \\
\hline & & & Female & 132 & 34.3 \\
\hline \multirow[t]{2}{*}{8} & 359 & 3.2 & Male & 202 & 56.3 \\
\hline & & & Female & 149 & 41.5 \\
\hline \multirow[t]{2}{*}{9} & 429 & 3.8 & Male & 252 & 58.7 \\
\hline & & & Female & 167 & 38.9 \\
\hline \multirow[t]{2}{*}{10} & 456 & 4.0 & Male & 286 & 62.7 \\
\hline & & & Female & 161 & 35.3 \\
\hline \multirow[t]{2}{*}{ II } & 583 & 5.2 & Male & 354 & 60.7 \\
\hline & & & Female & 208 & 35.7 \\
\hline \multirow[t]{2}{*}{12} & 670 & 5.9 & Male & 407 & 60.7 \\
\hline & & & Female & 246 & 36.7 \\
\hline \multirow[t]{2}{*}{13} & 705 & 6.2 & Male & 414 & 58.7 \\
\hline & & & Female & 274 & 38.9 \\
\hline \multirow[t]{2}{*}{14} & 842 & 7.4 & Male & 496 & 58.9 \\
\hline & & & Female & 328 & 39.0 \\
\hline \multirow[t]{2}{*}{15} & 864 & 7.4 & Male & 480 & 55.6 \\
\hline & & & Female & 362 & 41.9 \\
\hline \multirow[t]{2}{*}{16} & 1032 & 9.1 & Male & 594 & 57.6 \\
\hline & & & Female & 404 & 39.1 \\
\hline \multirow[t]{2}{*}{17} & 1198 & 10.6 & Male & 693 & 57.8 \\
\hline & & & Female & 472 & 39.4 \\
\hline \multirow[t]{2}{*}{ TOTAL } & | |,3 | 7 & $99.7 \% *$ & Male & 6654 & $58.8 * *$ \\
\hline & & & Female & 4350 & $38.4 * *$ \\
\hline
\end{tabular}

*Total not $100 \%$ due to rounding.

**Where \% does not equal $100 \%$, the data were 'unknown' or missing.

\section{Primary outcome}

From the dataset of 11,317 patients, a large number were excluded $(n=10,384)$ for having no documented pre- and post-analgesic pain score or where alternative analgesics or treatments were given, leaving 933 patients (Figure 1). Alternative analgesics were medicines not available to ambulance clinicians but either prescribed or administered by a third party (e.g. ketamine, diclofenac and co-codamol), while alternative treatments included immobilisation equipment such as splints, slings, bandages and dressings.

Average pain score reductions were established and compared against the standard ( $\geq 2$ out 10). Analgesics which achieved a clinically meaningful reduction in pain can be seen in Figure 2, along with descriptive statistics in Table 2 .

It was found that morphine sulphate IV, oral morphine, Entonox, paracetamol suspension and poly-analgesia all achieved a clinically meaningful reduction in pain when treating traumatically injured children in the pre-hospital setting. Paracetamol tablets did not achieve a clinically meaningful reduction in pain.

The median time taken between analgesic administration and final pain score varied between groups, with the shortest time being paracetamol tablets (10.5 minutes) and the longest being poly-analgesia (28 minutes).

\section{Secondary outcomes}

From 11,317 patients, $90.8 \%$ were assessed for pain. This included cases where the pain score was documented as 'unable to record' and 'patient refused'.

For patients who reported pain $(\mathrm{N}=7483), 51.6 \%(\mathrm{n}=$ 3861) were administered analgesia, 9.6\% $(n=717)$ received no analgesia but did receive alternative treatment and $38.8 \%(\mathrm{n}=2905)$ received no analgesia and no 


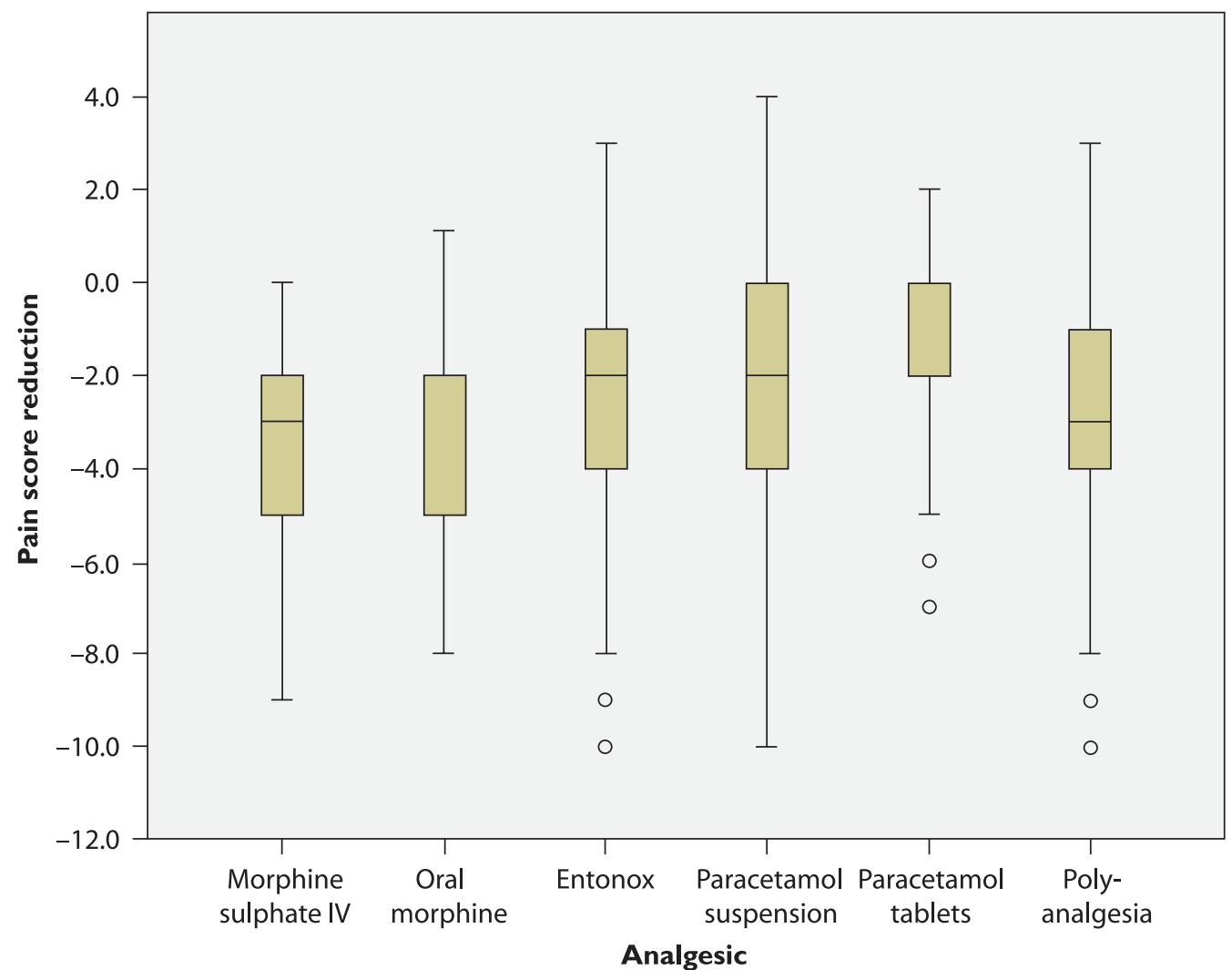

Figure 2. Median pain score reductions per analgesic.

Table 2. Descriptive statistics of each analgesic's pain score reduction.

\begin{tabular}{|c|c|c|c|c|c|c|c|}
\hline & & $\begin{array}{l}\text { Morphine } \\
\text { sulphate IV }\end{array}$ & $\begin{array}{l}\text { Oral } \\
\text { morphine }\end{array}$ & Entonox & $\begin{array}{l}\text { Paracetamol } \\
\text { suspension }\end{array}$ & $\begin{array}{l}\text { Paracetamol } \\
\text { tablets }\end{array}$ & Poly-analgesia \\
\hline $\mathbf{N}$ & & 48 & 39 & 245 & 236 & 168 & 197 \\
\hline Mean & & -3.40 & -3.074 & -2.824 & -2.015 & -0.929 & -3.048 \\
\hline Median & & -3.00 & -2.000 & -2.000 & -2.000 & 0.000 & -3.000 \\
\hline Std. deviation & & 2.285 & 2.3373 & 2.6189 & 2.4363 & 1.3996 & 2.6369 \\
\hline Minimum & & -9 & -8.0 & -10.0 & -10.0 & -7.0 & -10.0 \\
\hline Maximum & & 0 & 1.1 & 3.0 & 4.0 & 2.0 & 3.0 \\
\hline \multirow[t]{2}{*}{ IQR } & 25 & -5.00 & -5.000 & -4.000 & -4.000 & -2.000 & -4.000 \\
\hline & 75 & -2.00 & -2.000 & -1.000 & 0.000 & 0.000 & -1.000 \\
\hline
\end{tabular}

alternative treatment. Of the patients who received no analgesia and no alternative treatment $(\mathrm{n}=2905), 45 \%$ $(\mathrm{n}=1307), 36 \%(\mathrm{n}=1036)$ and $19 \%(\mathrm{n}=541)$ reported mild, moderate and severe pain, respectively. Twenty-one patients initially reported zero pain, therefore these were excluded.

The most commonly used analgesics were paracetamol $(45 \% ; n=2438)$, Entonox $(40 \% ; n=2141)$ and morphine $(15 \% ; n=836)$ (Figure 3).

From 933 eligible patients (Figure 1), morphine sulphate IV provided the most significant reduction in pain score. The median (range; IQR) reduction in pain per minute for morphine sulphate IV was $-0.189(-2.5$ to 0.0 ;
-0.294 and -0.085$)$ with paracetamol tablets $0.000(-2.0$ to $0.500 ;-0.116$ and 0.000 ) (Figure 4, Table 3 ).

Morphine sulphate IV was significantly more effective at reducing pain than paracetamol tablets $(\mathrm{P}<0.001)$ and paracetamol suspension ( $\mathrm{P}=0.001)$. Entonox was significantly more effective at reducing pain than paracetamol tablets $(\mathrm{P}<0.001)$ and paracetamol suspension $(\mathrm{P}=$ $0.003)$. Oral morphine was significantly more effective at reducing pain than paracetamol tablets $(\mathrm{P}<0.001)$. Polyanalgesia was significantly more effective at reducing pain than paracetamol tablets $(\mathrm{P}<0.001)$. Paracetamol suspension was significantly more effective at reducing pain than paracetamol tablets $(\mathrm{P}=0.005)$. 


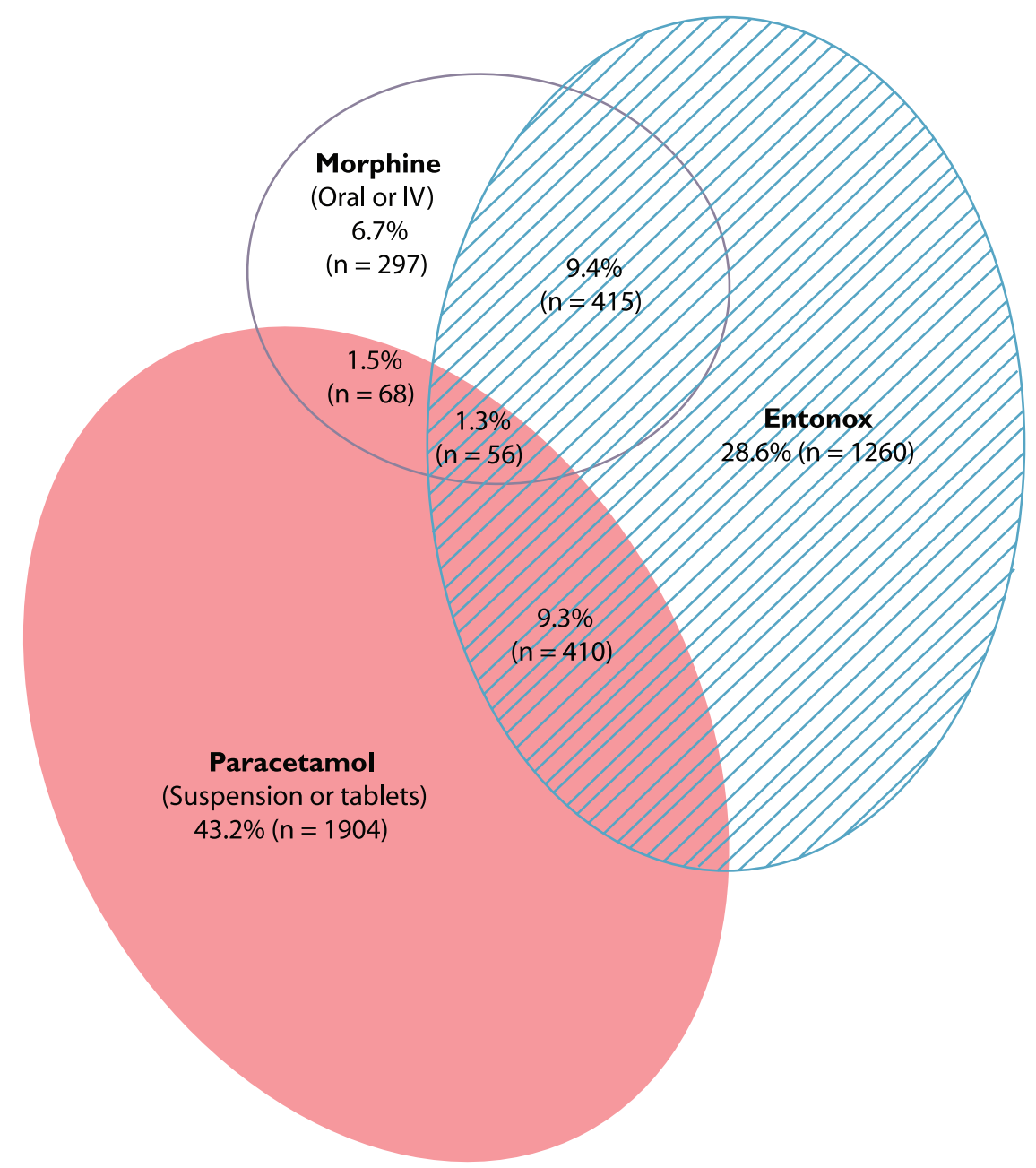

Figure 3. Venn diagram illustrating overall analgesic usage.

Venn diagram produced using eulerAPE software (Micallef \& Rodgers, 20I4) to illustrate overall usage of analgesics. Analgesics were grouped.

One patient received both oral and intravenous morphine.

\section{Discussion}

The UK Ambulance Services Clinical Practice Guidelines state that assessment should be undertaken for all children in pain, with regards to the severity, location, duration and nature (JRCALC, 2016). Based on the results of this service evaluation, this UK ambulance service NHS trust performed well, with pain scoring documented in $90.8 \%$ of cases which compared favourably against the London Ambulance Service NHS Trust (64\%) (Shaw et al., 2015).

The most concerning result was that only $51.6 \%$ $(\mathrm{n}=3861)$ of children reporting a pain score of $1-10$ were administered analgesia. It was acknowledged that other forms of non-pharmacological pain relief could be used, such as splinting, dressings or slings, for example. However, 38.8\% $(n=2905)$ of children reporting a pain score of 1-10 received no analgesia and no alternative treatment, when indeed these patients had moderate (4-6; $\mathrm{n}=1036)$ and severe $(7-10 ; \mathrm{n}=541)$ pain.

Comparing initial and final/destination pain scores may not take into consideration the time taken to achieve the reduction, therefore faster acting analgesics may not receive appropriate credit for reducing pain more quickly. It was also noted that a large number of patients $(n=1663)$ were excluded for not having a pre- and post-analgesic pain score documented. Pain management cannot be effectively evaluated without a pre- and post-analgesic pain score and therefore this should be a standard requirement.

All of the analgesics produced a clinically meaningful reduction in pain, except for paracetamol tablets. The time taken between analgesic administration and final pain score could not be controlled and there were significant differences between the groups. Calculating the pain score reductions per minute (Figure 4, Table 3) was a valuable consideration when determining the overall clinical significance of the analgesics. It was useful to compare Figure 2 and Figure 4, showing a similar pattern with morphine sulphate IV as the most effective analgesic and paracetamol tablets as the least effective. The most effective way to accurately measure pain score reduction would be regular pain scoring at short intervals postanalgesia, capturing rapid acting analgesics and distinguishing them from slower acting analgesics. Therefore, 


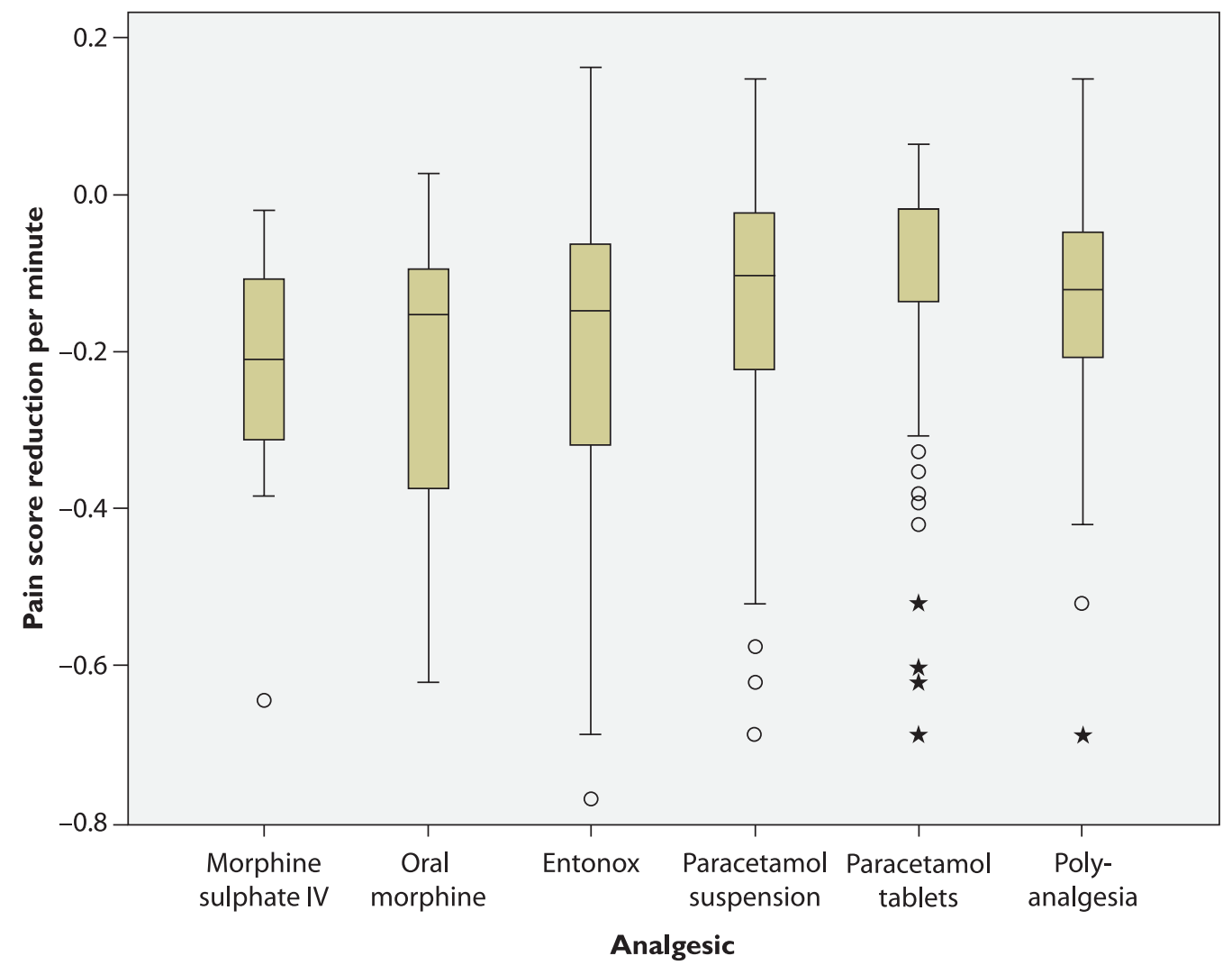

Figure 4. Median pain score reductions per minute per analgesic.

Table 3. Descriptive statistics of each analgesic's median pain score reduction per minute.

\begin{tabular}{|c|c|c|c|c|c|c|c|}
\hline & & $\begin{array}{l}\text { Morphine } \\
\text { sulphate IV }\end{array}$ & $\begin{array}{l}\text { Oral } \\
\text { morphine }\end{array}$ & Entonox & $\begin{array}{l}\text { Paracetamol } \\
\text { suspension }\end{array}$ & $\begin{array}{l}\text { Paracetamol } \\
\text { tablets }\end{array}$ & Poly-analgesia \\
\hline $\mathbf{N}$ & & 48 & 39 & 245 & 236 & 168 & 197 \\
\hline Median & & -0.189 & -0.133 & -0.128 & -0.083 & 0.000 & -0.100 \\
\hline Minimum & & -2.500 & -1.200 & -4.000 & -4.000 & -2.000 & -5.000 \\
\hline Maximum & & 0.000 & 0.048 & 0.182 & 0.400 & 0.500 & 0.667 \\
\hline \multirow[t]{2}{*}{ IQR } & 25 & -0.294 & -0.300 & -0.400 & -0.200 & -0.116 & -0.189 \\
\hline & 75 & -0.085 & -0.042 & -0.075 & 0.000 & 0.000 & -0.027 \\
\hline
\end{tabular}

a study taking pain score measurements at regular intervals would be useful.

\section{Limitations}

There were several limitations to the service evaluation. The 'free text' section of each PRF was not examined due to time and resource constraints. Therefore, if clinicians documented their analgesia or pain scores in the 'free text' section and not in the 'treatments' or 'observations' sections then these would not have been found. Data were not extracted from paper PRFs as this was not feasible for this study and therefore it is possible that we have missed some children. It was not possible to determine the number of excluded paper PRFs due to the scanning and verification process.
Another limitation was the sample size. Although there were 11,317 traumatically injured GCS 15 children, only 933 were used for comparing each analgesic, with the smallest group being oral morphine $(n=39)$.

\section{Implications for clinical practice}

The results of the evaluation have significant implications for clinical practice within this UK ambulance service NHS trust and should be implemented into practice through change. A service improvement plan should be developed to improve child pain scoring from $90.8 \%$ to $100 \%$. Treatment, either pharmacological or nonpharmacological, should be administered to all children who report pain, particularly moderate to severe pain. Furthermore, it should be made clear that a pre- and 
post-analgesic pain score should be obtained when administering analgesia in order to measure its effectiveness. These goals could be achieved by releasing clinical bulletins in the weekly newsletter that is sent to all front line clinicians across the service. Also, during the mandatory yearly training sessions, these issues should be reinforced.

\section{Implications for future research}

Recommendations for future research include performing a qualitative study to highlight the barriers and facilitators of analgesia administration in children. This would inform an educational intervention for paramedics around analgesia and pain assessment.

\section{Conclusion}

Analgesia currently available to ambulance clinicians working within this UK ambulance service NHS trust does produce a clinically meaningful reduction in pain when treating traumatically injured children. However, a large number of patients go untreated and it would be useful to explore reasons for this in further research.

\section{Acknowledgements}

We would like to thank Andrea Venn (medical statistician) for her assistance with the statistical analysis. We would also like to thank the UK Ambulance Service NHS Trust for sharing its electronic data.

\section{Author contributions}

GAW: Responsible for conception, approvals, study design, data management, data analysis, interpretation and conclusions.

FB-H: Responsible for approvals, study design, interpretation and conclusions.

Both authors contributed to the development of the manuscript and agreed on the final version.

\section{Conflict of interest}

None declared.

\section{Funding}

The project formed part of an MSc qualification, of which the dissertation module was funded by East Midlands Ambulance Service NHS Trust.

\section{References}

Bulloch, B., \& Tenenbein, M. (2002). Assessment of clinically significant changes in acute pain in children. Academic Emergency Medicine, 9, 199-202.

Farrar, J. T., Berlin, J. A., \& Strom, B. L. (2003). Clinically important changes in acute pain outcome measures: A validation study. Journal of Pain and Symptom Management, 25, 406-411.

Farrar, J. T., Young, J. P Jr., LaMoreaux, L., Werth, J., \& Poole, R. (2001). Clinical importance of changes in chronic pain intensity measured on an 11-point numerical pain rating scale. Pain, 94, 149-158.

Halbsguth, U., Rentsch, K. M., Eich-Höchli, D., Diterich, I., \& Fattinger, K. (2008). Oral diacetylmorphine (heroin) yields greater morphine bioavailability than oral morphine: Bioavailability related to dosage and prior opioid exposure. British Journal of Clinical Pharmacology, 66, 781-791.

Heinrich, M., Menzel, C., Hoffmann, F., Berger, M., \& Schweinitz, Dv. (2015). Self-administered procedural analgesia using nitrous oxide/oxygen (50:50) in the pediatric surgery emergency room: Effectiveness and limitations. European Journal of Pediatric Surgery, 25, 250-256.

Hennes, H., Kim, M. K., \& Pirrallo, R. G. (2005). Prehospital pain management: A comparison of providers' perceptions and practices. Prehospital Emergency Care, 9, 32-39.

Joint Royal Colleges Ambulance Liaison Committee (JRCALC). (2016). UK Ambulance Services Clinical Practice Guidelines 2016. Warwick, England: Class Professional Publishing.

Micallef, L., \& Rodgers, P. (2014). eulerAPE: Drawing areaproportional 3-venn diagrams using ellipses. PLOS ONE, 9, e101717.

Murphy, A., Barrett, M., Cronin, J., McCoy, S., Larkin, P., Brenner, M., ... O'Sullivan, R. (2014). A qualitative study of the barriers to prehospital management of acute pain in children. Emergency Medicine Journal, 31, 493-498.

Myrvik, M. P., Brandow, A. M., Drendel, A. L., Yan, K., Hoffman, R. G., \& Panepinto, J. A. (2013). Clinically meaningful measurement of pain in children with sickle cell disease. Pediatric Blood \& Cancer, 60, 1689-1695.

Reigart, J. R., Chamberlain, K. H., Eldridge, D., O’Brien, E. S., Freeland, K. D., Larsen, P., ... Hartzog, T. H. (2012). Peripheral intravenous access in pediatric inpatients. Clinical Pediatrics, 51, 468-472.

Samuel, N., Steiner, I. P., \& Shavit, I. (2015). Prehospital pain management of injured children: A systematic review of current evidence. American Journal of Emergency Medicine, 33, 451-454.

Shaw, J., Fothergill, R., \& Virdi, G. (2015). Improving prehospital paediatric pain management. Emergency Medicine Journal, 32, e13-e14.

Swor, R., McEachin, C. M., Seguin, D., \& Grail, K. H. (2005). Prehospital pain management in children suffering traumatic injury. Prehospital Emergency Care, 9, 40-43. 